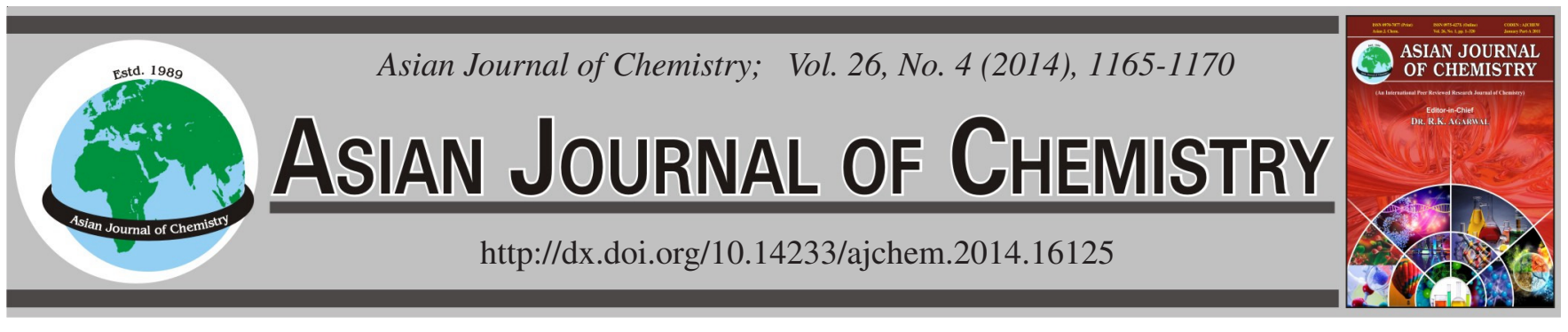

\title{
Parameter Optimization of Ultrasound Technology for Algae Removal and its Application in Pengxi River of Three Gorges Reservoir
}

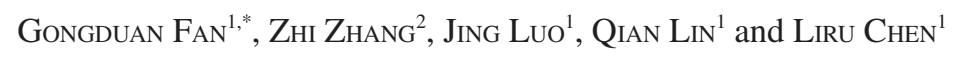

${ }^{1}$ College of Civil Engineering, Fuzhou University, Fuzhou 350108, Fujian Province, P.R. China

${ }^{2}$ Key Laboratory of the Three Gorges Reservoir Region's Eco-environment under the State Ministry of Education, Chongqing University, Chongqing 400045, P.R. China

*Corresponding author: Fax: +86 591 22865355; Tel: +86 591 22865361; E-mail: fgdfz@fzu.edu.cn; cqufgd@126.com

Received: 31 July 2013;

Accepted: 17 December 2013;

Published online: 15 February 2014;

AJC-14721

The effects on algae removal imposed by ultrasound technology employing different combinations of parameters, including frequency, power and irradiation time, were estimated using response surface methodology. This technology was applied in the backwater area of Pengxi river in the three Gorges Reservoirs. Results showed that, the algae removal rate by ultrasound was $64.1 \%$, at an optimal frequency of $45 \mathrm{kHz}$, input power of $60 \mathrm{~W}$ and irradiation time of $48 \mathrm{~s}$. After $2 \mathrm{~h}$ of ultrasound irradiation on the $500 \mathrm{~m}^{2}$ study field, the algae density dropped from $(1.10 \pm 0.02) \times 10^{7}$ to $(2.1 \pm 0.1) \times 10^{6}$ cells $/ \mathrm{mL}$. Chlorophyll-a concentration dropped to $13.8 \%$ of its initial amount algae were effectively controlled. Ultrasound technology is concluded to be effective for algae removal and can thus be applied to algal blooms.

Keywords: Algae removal, Response surface design, Ultrasound, Water bloom.

\section{INTRODUCTION}

Eutrophication is currently one of the major water pollution problems in the world ${ }^{1}$. In eutrophic water, the "water bloom" formed by rapid algal growth, results in the deterioration of water quality, reduction of aquatic species, as well as other ecological system disorders. Even worse, a number of algae species (Microcystis sp., Anabaena sp., etc.) produce algal toxins. These toxins affect a variety of aquatic and semiaquatic animals ${ }^{2}$ and can threaten human health through the food chain ${ }^{3}$. Other algae species also directly or indirectly threaten human health by causing rashes, gastrointestinal diseases, pneumonia ${ }^{4}$, allergic reactions, headache, fever ${ }^{5}$ and liver cancer ${ }^{6}$. The outbreak of blue-green algae in Taihu Lake in May 2007 imposed serious effects on the lives of the people residing near the $\operatorname{area}^{7}$. Therefore, the control of eutrophication has emerged as a pressing and challenging issue.

Water blooms are currently controlled via chemical ${ }^{8,9}$, biological ${ }^{10}$ and physical methods ${ }^{11,12}$, among others. Chemical methods require the addition of pharmaceutical products onto the water, which easily results in secondary pollution. Moreover, the cost for such methods is relatively high. Biological methods entail low cost, but their effects are not immediately evident. Hence, biological methods are unsuitable for emergency treatment of algal blooms.

Ultrasound technology has recently been used in environmental applications. The principle behind this technology lies in the use of various effects of ultrasound to inhibit the growth of algae ${ }^{13,14}$. The use of this technology has a number of advantages. First, ultrasound is easy to control and does not involve the use of chemicals. Second, the technology has mild reaction conditions and quick reaction speed. Thus, the ultrasound technology is considered environment friendly, which gives it a broad development prospect.

The use of ultrasound technology for algae removal currently focuses on control parameters, mechanisms and practical applications ${ }^{13-15}$. However, the control parameters and the mechanism of this technology remain indefinite. Moreover, this technology has limited practical applications and its manner of operation is not clear. Various studies on the optimal frequency for ultrasound technology have reported largely different values, including $580^{16}, 150^{17}, 1700^{18-20}, 200^{21}$ and $80^{22} \mathrm{kHz}$. Similarly, different studies have reported largely different values for optimal power, including $30^{17}, 60^{23}, 80^{22}, 120^{24}$ and $1200^{21} \mathrm{~W}$, as well as $0.6^{20}, 47.2^{25}$ and $0.0018^{16} \mathrm{~W} / \mathrm{cm}^{3}$. Optimal values for irradiation time include $5^{23} \mathrm{~s}, 5^{22}$ and $10^{21} \mathrm{~min}$. These differences can primarily be attributed to the interaction among the control parameters. The optimal values for the control parameters can be obtained through actual optimization.

In this paper, we designed and optimized the control parameters for ultrasound technology by conducting a response surface experiment. The designed and optimized parameters include ultrasonic frequency, ultrasonic power and ultrasonic 
irradiation time. Through this experiment, we achieved an optimal combination of the ultrasound parameters, which we used in a field study on the backwater area of Pengxi river in the three Gorges Reservoir. This study aims at providing an effective and scientific basis for the application of ultrasound technology and for the effective prevention of eutrophication.

\section{EXPERIMENTAL}

The algae species used in this laboratory research were taken below the Double River Bridge spanning Pengxi river. After identification, we ascertained that the predominant algae species in the collection site were Microcystis sp. and Anabaena sp., which belong to Cyanobacteria and Scenedesmus, respectively. We placed the algae in a constant-light incubator to inactivate the culture. The temperature was set to $25^{\circ} \mathrm{C}$, light intensity to $2000 \mathrm{~lx}$ and the light-dark cycle to $14 \mathrm{~h}: 10 \mathrm{~h}$. The algae were initially cultivated in the prepared monoculture BG11, which was provided by the Freshwater Algae Culture Collection of the Institute of Hydrobiology. The composition of BG11 was $1.5 \mathrm{~g} / \mathrm{L} \mathrm{NaNO}_{3}, 0.04 \mathrm{~g} / \mathrm{L} \mathrm{K}_{2} \mathrm{HPO}_{4} \cdot 3 \mathrm{H}_{2} \mathrm{O}, 0.075$ $\mathrm{g} / \mathrm{L} \mathrm{MgSO}_{4} \cdot 7 \mathrm{H}_{2} \mathrm{O}, 0.036 \mathrm{~g} / \mathrm{L} \mathrm{CaCl}_{2} \cdot 2 \mathrm{H}_{2} \mathrm{O}, 0.006 \mathrm{~g} / \mathrm{L}$ citric acid, $0.006 \mathrm{~g} / \mathrm{L}$ ferric ammonium citrate, $0.001 \mathrm{~g} / \mathrm{L}$ EDTA, $0.02 \mathrm{~g} / \mathrm{L}$ $\mathrm{Na}_{2} \mathrm{CO}_{3}$ and $1 \mathrm{~mL} / \mathrm{L} \mathrm{A}_{5}+$ Co solution. The composition of the $\mathrm{A}_{5}+$ Co solution was $2.86 \mathrm{~g} / \mathrm{L} \mathrm{H}_{3} \mathrm{BO}_{3}, 1.86 \mathrm{~g} / \mathrm{L} \mathrm{MnCl}_{2} \cdot 4 \mathrm{H}_{2} \mathrm{O}$, $0.22 \mathrm{~g} / \mathrm{L} \mathrm{ZnSO} \cdot 7 \mathrm{H}_{2} \mathrm{O}, 0.39 \mathrm{~g} / \mathrm{L} \mathrm{Na} \mathrm{MoO}_{4} \cdot 2 \mathrm{H}_{2} \mathrm{O}, 0.08 \mathrm{~g} / \mathrm{L}$ $\mathrm{CuSO}_{4} \cdot 5 \mathrm{H}_{2} \mathrm{O}$ and $0.05 \mathrm{~g} / \mathrm{L} \mathrm{Co}\left(\mathrm{NO}_{3}\right)_{2} \cdot 6 \mathrm{H}_{2} \mathrm{O}$. The $\mathrm{pH}$ value of the BG11 medium was 7.1, which was regulated using $\mathrm{NaOH}$ or $\mathrm{HCl}$. The algae were cultivated until their density reached $10^{7}$ cells $/ \mathrm{mL}$. At this concentration, the algae liquid can be used for the ultrasonic experiment.

Ultrasonic algae removal device: The device used in this study was developed by the Institute of Acoustics of the Chinese Academy of Sciences. The other parts of reactor were homemade. The experimental setup is shown in Fig. 1. The ultrasound source was an ATANA AT3020 ultrasonic signal generator. The power amplifier with model number HFVA-62 was from Nanjing Foneng Co., Ltd. The oscilloscope with model number was UT2025C was produced by Hong Kong Unit Co.

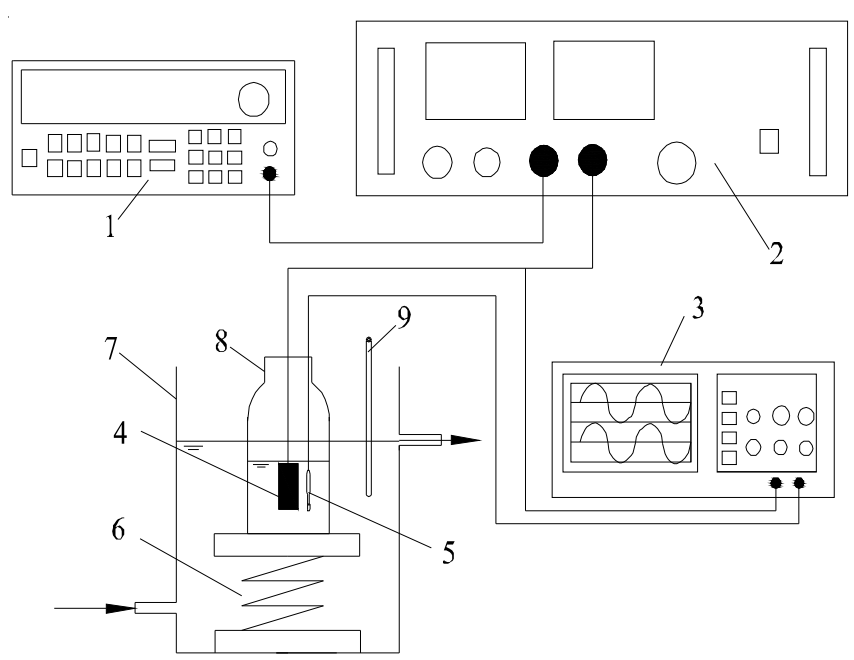

Fig. 1. Experimental ultrasonic apparatus (1. signal generator; 2. power amplifier; 3. oscilloscope; 4. transducer; 5. hydrophone; 6. telescopic stand; 7. cooling device; 8. glass flask 9. thermometer)
Detection of experimental parameters: In this study, the detected parameters were in vivo chlorophyll-a (in vivo Chl-a) content of the algae and algal density, which were measured during both laboratory testing and field testing using the AquaFluor Handheld Fluorometer produced by Turner Designs (USA). This instrument requires calibration before use. Water samples were taken and the steps listed in the "Analysis Editorial Board. Water and wastewater monitoring analysis method (4th Edition) (add Edition)" were followed for testing. The resulting value from the test and the water sample were used in the calibration. The instrument was only used for experimental testing when the correlation between the results of the standard and the experimental test groups was $99.9 \%$. In the detection of in vivo chlorophyll-a, blue light with a wavelength of $430 \mathrm{~nm}$ was chosen; the detection range was 0.3 to $3 \mu \mathrm{g} / \mathrm{L}$. Yellow light with a wavelength of $590 \mathrm{~nm}$ was chosen in the determination of algae density. The detection range was 150 cells $/ \mathrm{mL}$ to 150000 cells $/ \mathrm{mL}$. When the actual density exceeded the maximum range for the instrument, the sample was diluted. The immediate chlorophylla removal rate used in this experiment was calculated using eqn. (1).

$$
\text { Removal of chlorophyll }-\mathrm{a}=\frac{\mathrm{Chl}-\mathrm{a}_{0}-\mathrm{Chl}-\mathrm{a}_{1}}{\mathrm{Chl}-\mathrm{a}_{0}} \times 100 \% \text { (1) }
$$

where Chl- $\mathrm{a}_{0}$ is the in vivo Chl-a concentration $(\mu \mathrm{g} / \mathrm{L})$ in the algae before ultrasonic treatment and $\mathrm{Chl}-\mathrm{a}_{1}$ is the in vivo Chla concentration $(\mu \mathrm{g} / \mathrm{L})$ in the algae after ultrasonic treatment.

Response-surface experimental design for ultrasonic parameters optimization: Ultrasonic power, ultrasonic frequency and ultrasonic irradiation time are the three main parameters of ultrasonic algae removal. Based on comprehensive pre-testing and considering energy consumption and costs, we chose the following parameter values for this experiment: frequency range, 20 to $120 \mathrm{kHz}$; power range, 20 to $60 \mathrm{~W}$; and irradiation time, $10 \mathrm{~s}$ to $50 \mathrm{~s}$. Based on the principles of the response surface central composite design, we designed a test program that includes three factors and three levels, totaling 20 test points. The assignment of factors and levels are shown in Table-1. The response surface experimental design is shown in Table-2. Data were processed by the design-expert software. For each experimental group, an $800 \mathrm{~mL}$ sample was used. The ultrasonic transducer was submerged $30 \mathrm{~mm}$ below the water surface. Ultrasound with different frequencies and power was applied to the samples at various lengths of irradiation time. The supernatant of the samples was subsequently used to determine the in vivo Chla concentration. The algal density and vivo Chl-a concentration were detected after ultrasonic after $2 \mathrm{~h}$ stationary sampling.

\section{Field experiment}

Experimental site: In this study, the testing site was a $500 \mathrm{~m}^{2}$ backwater area near the double river bridge spanning Pengxi river in the three Gorges Reservoir. In this area, the water flow is slow. Hence, the effect of water flow can be disregarded. The temperature during the experiment ranged from 23.5 to $31.2{ }^{\circ} \mathrm{C}$, with an average of $27^{\circ} \mathrm{C}$. Light conditions were good and suitable for algal growth. 


\begin{tabular}{|c|c|c|c|c|c|}
\hline \multicolumn{6}{|c|}{$\begin{array}{l}\text { TABLE-1 } \\
\text { FACTORS AND LEVELS OF THE SMALL-SCALE LABORATORY EXPERIMENTAL DESIGN }\end{array}$} \\
\hline \multirow{2}{*}{ Factor } & \multirow{2}{*}{ Variable } & \multirow{2}{*}{ Units } & \multicolumn{3}{|c|}{$\begin{array}{ll}\text { Level } \\
\end{array}$} \\
\hline & & & -1 (low) & 0 & +1 (high) \\
\hline Ultrasonic Frequency & $\mathrm{X}_{1}$ & $\mathrm{kHz}$ & 20.00 & 70.00 & 120.00 \\
\hline Ultrasonic Power & $\mathrm{X}_{2}$ & W & 20.00 & 40.00 & 60.00 \\
\hline Irradiation Time & $X_{3}$ & $\min$ & 10 & 30 & 50 \\
\hline
\end{tabular}

Pengxi river is an important tributary of the Yangtze river and is located in the hinterland of the three Gorges Reservoir area. The river is in within the territory of Yunyang County and Kaixian and has a basin area of $5172.5 \mathrm{~km}^{2}$, main river length of $182.4 \mathrm{~km}$ and annual average runoff of 3.41 billion $\mathrm{m}^{3}$.

The catchment area of Pengxi river in Yunyang County was initially $609.2 \mathrm{~km}^{2}$ with a length of $50.4 \mathrm{~m}$. After the three Gorges Reservoir was formed, the flood area of Pengxi river decreased to $92 \mathrm{~km}^{2}$, the migrant population in the area reached 221.5 thousand and a fluctuation zone with an area of approximately $65 \mathrm{~km}^{2}$ formed. Among the tributaries of the three Gorges Reservoir, Pengxi river has the largest flood area, the largest number of immigrants and the most widely fluctuating area. From 2005 to 2007, the water quality of the Pengxi river section of the reservoir was Class IV. Currently, the number of months during which the water quality of this section is Class IV is increasing. Water bloom occurs almost every year with a worsening trend. Therefore, emergency measures for bloom control are desperately needed.

Mobile boat ultrasonic algae removal device: In this test, 20 ultrasonic transducers were used. The transducers were installed on both sides of a boat spaced at $1.4 \mathrm{~m}$. The optimal parameters of the mobile boat, such as power and frequency, were obtained by optimizing the experimental design. The launch direction of the ultrasonic transducers was perpendicular to the boat. The launcher was installed $25 \mathrm{~cm}$ below the water surface to ensure that the ultrasound emission was horizontal. The elevation and the plan of the mobile boat with ultrasonic transducer. The full length of the boat was $11.5 \mathrm{~m}$, full width was $3.2 \mathrm{~m}$, draft was $0.3 \mathrm{~m}$ to $0.5 \mathrm{~m}$ and speed was $16 \mathrm{~km} / \mathrm{h}$. The boat was made of glass fiber-reinforced plastic. Treatment and control groups were established. Treatment group samples were taken upstream, whereas control group samples were taken approximately $500 \mathrm{~m}$ from the treatment group area. During testing, the boat with ultrasonic transducer sailed a round trip in the water for $2 \mathrm{~h}$ each day. Boat speed was maintained at $50 \mathrm{~m} / \mathrm{h}$ when ultrasonic transducers were on.

In the area of the treatment groups, the boat maintained the same speed and travelled for $2 \mathrm{~h}$ while the ultrasonic transducers were off. Samples were collected immediately in the middle of the water and were tested in the field for algae density and in vivo Chl-a concentration for six times. For the control group, the same procedure was performed six times in the area $500 \mathrm{~m}$ upstream of the test area.

\section{RESULTS AND DISCUSSION}

The result of the response surface experiment for the optimized parameters of ultrasonic algae removal is presented in Table-2.
The experimental data were used for polynomial regression analysis. The response design was suitable for the secondorder model, which is an experience model that can describe the relationship between response variables (dependent variable) and independent variables (operating conditions), as shown in eqn. (2):

$$
Y=\beta_{0}+\sum_{\mathrm{i}=1}^{\mathrm{k}} \beta_{\mathrm{i}} \mathrm{X}_{\mathrm{i}}+\sum_{\mathrm{i}=1}^{\mathrm{k}} \beta_{\mathrm{ii}} \mathrm{X}_{\mathrm{ii}}^{2}+\sum_{1 \leq \mathrm{i} \leq \mathrm{j} \leq \mathrm{k}}^{\mathrm{k}} \beta_{\mathrm{ij}} \mathrm{X}_{\mathrm{i}} \mathrm{X}_{\mathrm{j}}
$$

where $y$ is the predicted response value; $\beta_{0}, \beta_{\mathrm{i}}$ and $\beta_{\mathrm{ii}}$ are the offset term and second-order linear offset and offset coefficients, respectively; $\beta_{\mathrm{ij}}$ is the interaction coefficient; $\mathrm{X}_{\mathrm{i}}$ and is the coded value of the independent variable. The conversion equation between $\mathrm{X}_{\mathrm{i}}$ and the actual value of the variable tested is shown in eqn. (3):

$$
\mathrm{X}_{\mathrm{i}}=\frac{2\left[\mathrm{x}_{\mathrm{i}}-\mathrm{x}_{\mathrm{i}}(\text { at level } 0)\right]}{\mathrm{x}_{\mathrm{i}}(\text { at high level })-\mathrm{x}_{\mathrm{i}}(\text { at log level })}
$$

According to the mathematical model and the results of the variance analysis shown in Table-3, individually, all of the factors, interaction terms and their squares significantly affect on the removal rate of chlorophyll-a. The regression equation is:

$$
\begin{gathered}
Y=18.853+0.822 \mathrm{X}_{1}+1.7185 \mathrm{X}_{2}+0.537 \mathrm{X}_{3} \\
-7.319 \times 10^{-3} \mathrm{X}_{1} \mathrm{X}_{2}-1.984 \mathrm{X}_{1} \mathrm{X}_{3}+0.011 \mathrm{X}_{2} \mathrm{X}_{3} \\
-3.242 \times 10^{-3} \mathrm{X}_{1}^{2}-0.016 \mathrm{X}_{2}^{2}-0.013 \mathrm{X}_{3}^{2}
\end{gathered}
$$

where $\mathrm{Y}$ is the response value of the removal rate of Chl-a; and $X_{1}, X_{2}$ and $X_{3}$ stand for ultrasonic frequency, power and irradiation time, respectively.

A large F-value and a small P-value represent significance of the correlation coefficient of variables ${ }^{26}$. From the analysis of variance shown in Table-3, the F-value of the model was 152.01, Prob $>F<0.0001$ (Prob' $>F^{\prime}<0.05$, models are significant) and lack of fit was insignificant (Prob $>$ F value was 0.3798 , which is greater than 0.05). All the values above indicate that the model was significant. That is, the model fits well in the entire regression area. The multiple correlation coefficient obtained was $\mathrm{R}^{2}=0.9927$, indicating a good correlation. $\mathrm{RA}_{\mathrm{dj}}{ }^{2}-\mathrm{R}_{\text {Pred }}{ }^{2}=0.9862-0.9520=0.0342<0.2, \mathrm{CV}=2.58 \%<$ $10 \%$, showing that the credibility and accuracy of the experiment are both high (Table-4). $\mathrm{A}_{\text {deq }}$ precision is a ratio of effective signal to noise and its value was 37.414 , which can be considered reasonable given the values above 4 .

The regression equation provides a suitable model for the removal of algae using ultrasonic technology. The test for significance using the regression coefficients of the quadratic regression model showed that the factors $X_{1}, X_{2}$ and $X_{3}$, are linearly correlated to in vivo Chl-a removal rate. $\mathrm{X}_{1}, \mathrm{X}_{2}, \mathrm{X}_{1}$, $\mathrm{X}_{3}, \mathrm{X}_{2}$ and $\mathrm{X}_{3}$ have clear effects on the removal rate of 
TABLE-2

CENTRAL COMPOSITE DESIGN TEST SCHEME AND RESULTS

\begin{tabular}{|c|c|c|c|c|c|c|c|c|c|}
\hline \multirow{2}{*}{ No. } & \multicolumn{3}{|c|}{ Factors } & \multirow{2}{*}{$\frac{\text { Response }}{\mathrm{Y}}$} & \multirow{2}{*}{ No. } & \multicolumn{3}{|c|}{ Factors } & \multirow{2}{*}{$\frac{\text { Response }}{\mathrm{Y}}$} \\
\hline & $X_{1}$ & $\mathrm{X}_{2}$ & $X_{3}$ & & & $X_{1}$ & $\mathrm{X}_{2}$ & $\mathrm{X}_{3}$ & \\
\hline 1 & 20 & 20 & 10 & 26.17 & 11 & 70 & 20 & 30 & 49.79 \\
\hline 2 & 120 & 20 & 10 & 48.1 & 12 & 70 & 60 & 30 & 59.5 \\
\hline 3 & 20 & 60 & 10 & 43.33 & 13 & 70 & 40 & 10 & 54.15 \\
\hline 4 & 120 & 60 & 10 & 33.68 & 14 & 70 & 40 & 50 & 58.6 \\
\hline 5 & 20 & 20 & 50 & 28.45 & 15 & 70 & 40 & 30 & 59.85 \\
\hline 6 & 120 & 20 & 50 & 40.5 & 16 & 70 & 40 & 30 & 59.05 \\
\hline 7 & 20 & 60 & 50 & 61.45 & 17 & 70 & 40 & 30 & 61.1 \\
\hline 8 & 120 & 60 & 50 & 46.53 & 18 & 70 & 40 & 30 & 61.92 \\
\hline 9 & 20 & 40 & 30 & 52.84 & 19 & 70 & 40 & 30 & 59.16 \\
\hline 10 & 120 & 40 & 30 & 53.13 & 20 & 70 & 40 & 30 & 59.07 \\
\hline
\end{tabular}

TABLE-3

ANALYSIS OF VARIANCE OF THE REGRESSION EQUATION

\begin{tabular}{|c|c|c|c|c|c|c|}
\hline Source & Sum of Squares & df & Mean Square & F Value & p-value Prob $>$ F & Note \\
\hline Model & 2359.19 & 9 & 262.13 & 152.01 & $<0.0001$ & significant \\
\hline $\mathrm{X}_{1}$ & 9.41 & 1 & 9.41 & 5.46 & 0.0416 & significant \\
\hline$X_{2}$ & 265.02 & 1 & 265.02 & 153.68 & $<0.0001$ & significant \\
\hline $\mathrm{X}_{3}$ & 90.60 & 1 & 90.60 & 52.54 & $<0.0001$ & significant \\
\hline $\mathrm{X}_{1} \mathrm{X}_{2}$ & 428.51 & 1 & 428.51 & 248.49 & $<0.0001$ & significant \\
\hline $\mathrm{X}_{1} \mathrm{X}_{3}$ & 28.69 & 1 & 28.69 & 16.64 & 0.0022 & significant \\
\hline$X_{2} X_{3}$ & 164.62 & 1 & 164.62 & 95.46 & $<0.0001$ & significant \\
\hline $\mathrm{X}_{1}^{2}$ & 180.65 & 1 & 180.65 & 104.76 & $<0.0001$ & significant \\
\hline $\mathrm{X}_{2}^{2}$ & 114.23 & 1 & 114.23 & 66.24 & $<0.0001$ & significant \\
\hline $\mathrm{X}_{3}^{2}$ & 61.14 & 1 & 61.14 & 35.45 & 0.0001 & significant \\
\hline Residual & 17.24 & 10 & 1.72 & & & \\
\hline Lack of Fit & 9.86 & 5 & 1.97 & 1.33 & 0.3798 & not significant \\
\hline Pure Error & 7.39 & 5 & 1.48 & & & \\
\hline Cor Total & 2376.44 & 19 & & & & \\
\hline
\end{tabular}

TABLE 4

MODEL RELIABILITY ANALYSIS

\begin{tabular}{ccccccccc}
\hline \multicolumn{1}{c}{ Index } & Std. Dev. & Mean & C.V $(\%)$ & PRESS $^{*}$ & R $^{2}$ & Adj R $^{2}$ & Pred R $^{2}$ & Adeq precision $^{2}$ \\
\hline Results & 1.31 & 50.82 & 2.58 & 114.07 & 0.9927 & 0.9862 & 0.9520 \\
\hline *Press: Predicted residual error sum of squares & & & &
\end{tabular}

chlorophyll-a. $\mathrm{X}_{12}, \mathrm{X}_{22}$ and $\mathrm{X}_{32}$ have a clear curved surface effect on the removal rate of in vivo Chl-a.

Based on the analysis of data using eqn. (4), with dimensionality reduction, the effect of the two factors on the removal rate of chlorophyll-a when the conditions of the other factors are unchanged can be observed. The response surface plots and contour maps from the design-expert analysis are shown in Fig. 2.

Fig. $2 \mathrm{a}$ and $2 \mathrm{~b}$ show the effect of ultrasonic power and ultrasonic frequency on removal rate of chlorophyll-a when ultrasonic irradiation time was unchanged (center value). When the shape of the contour line is oval, the interaction between the factors is significant. When the shape is circular, the interaction between factors is insignificant. Therefore, the interaction between the ultrasonic power and ultrasonic frequency was significant, as reflected by the contour map. From the response surface graph, a high removal rate of chlorophyll-a can be achieved with low frequency ultrasound (20 to $80 \mathrm{kHz}$ ) and high ultrasonic power (40 to $60 \mathrm{~W}$ ).

Figs. $2 \mathrm{c}$ and $2 \mathrm{~d}$ show the effect of ultrasonic power and ultrasonic irradiation time on the removal rate of chlorophylla when the ultrasonic frequency was unchanged (center value). Research shows that increasing the ultrasonic power and ultrasonic irradiation time can help improve the removal rate of chlorophyll-a. To obtain the desired removal rate, the ultrasonic power and ultrasonic irradiation time should be in the within 40 to $60 \mathrm{~W}$ and 30 to $50 \mathrm{~s}$, respectively.

Figs. 2e and $2 \mathrm{f}$ show the effect of ultrasonic frequency and ultrasonic irradiation time on the removal rate of chlorophyll-a when ultrasonic power was unchanged (center value). The contour map shows that the interaction between these two parameters is insignificant. When the ultrasonic frequency increased from 20 to $70 \mathrm{kHz}$, the removal rate of chlorophylla increased. However, when the ultrasonic frequency continued to increase, the removal rate decreased. This phenomenon indicated that, the optimal value of ultrasonic frequency is approximately $70 \mathrm{kHz}$. Given that the interaction between ultrasonic frequency and irradiation time was insignificant, the irradiation time should be kept at 30 to $50 \mathrm{~s}$ to ensure high algae removal rate.

A stable point exists in the regression equation and this point represents the maximum value. By solving the inverse model, the maximum values for the major factors were obtained: $X_{1}=45, X_{2}=60$ and $X_{3}=48$. Hence, the optimal conditions were $45 \mathrm{kHz}$ for ultrasound frequency, $60 \mathrm{~W}$ for ultrasonic power and $48 \mathrm{~s}$ for ultrasonic irradiation time. The removal rate of chlorophyll-a can reach $64.1 \%$. 

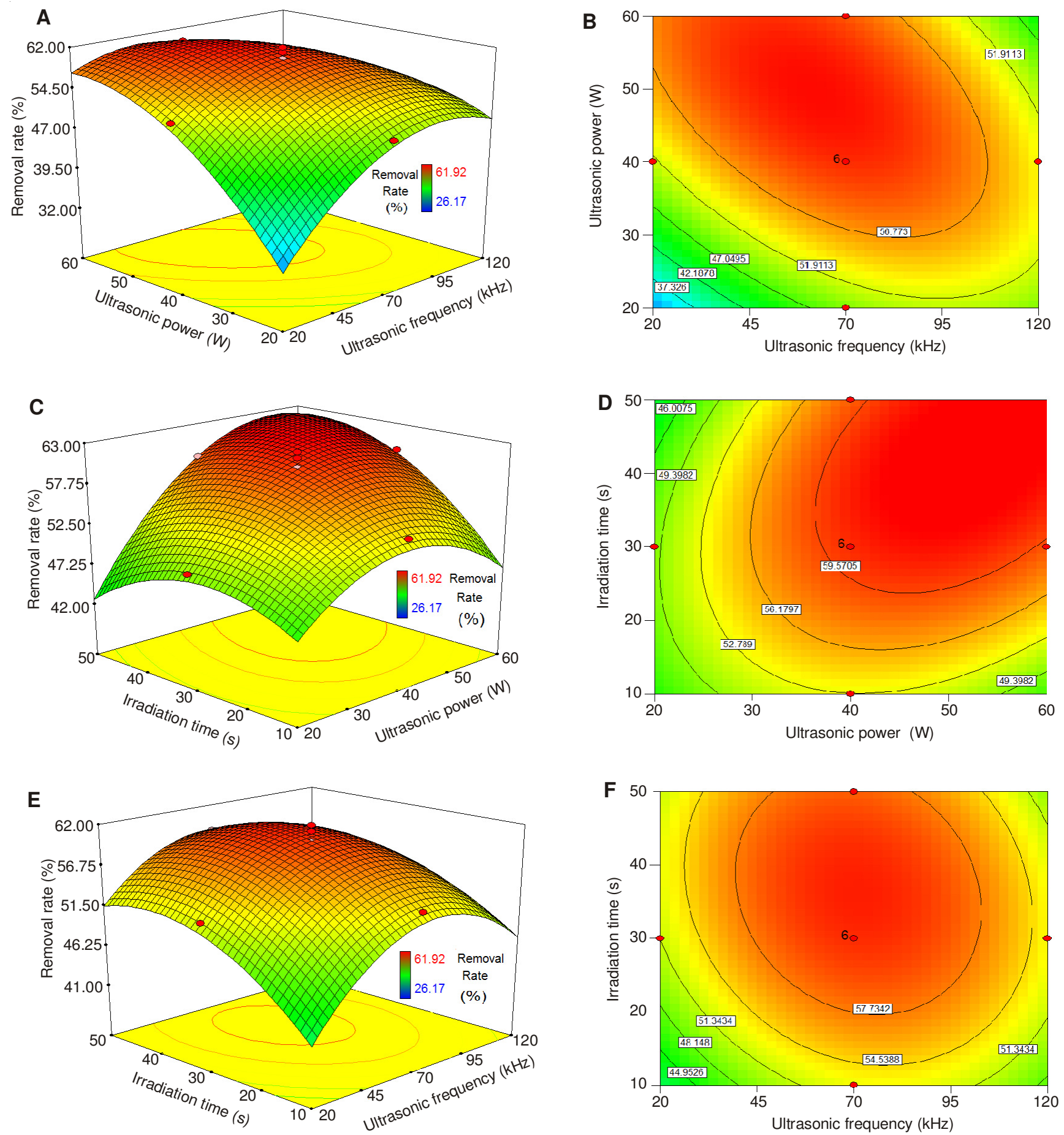

Fig. 3. Response surface plot of removal rate as a function of ratio of (a) frequency and ultrasonic power 3D; (b) frequency and ultrasonic power 2D; (c) irradiation time and ultrasonic power 3D; (d) irradiation time and ultrasonic power 2D; (e) irradiation time and ultrasonic frequency 3D; and (f) irradiation time and ultrasonic frequency $2 \mathrm{D}$

To verify the predicted results, the calculated optimum conditions of $(45 \mathrm{kHz}, 60 \mathrm{~W}$ and $48 \mathrm{~s})$ were used in the experiment. The initial concentration of algae in the verification test was also used in the experiment using the optimal conditions to eliminate the effects on the model. In this experiment, three test groups and a control group were prepared and an average removal rate of $64.4 \%$ was obtained. The removal rate obtained from the regression equation is similar to this result and the error is only $0.47 \%$. This finding indicated that the test value and the predicted value were consistent and proved that the model is accurate and reliable for analyzing and predicting the parameters of ultrasonic algae removal.

Results and analysis of the field test: Based on the conclusion of the optimal experiment, the optimal parameters of the ultrasonic transducer were a power of $60 \mathrm{~W}$ and frequency of $45 \mathrm{kHz}$. As the distance from the transducer increased, ultrasonic intensity decreased; the effective functional range of the transducer was $50 \mathrm{~cm}$. To ensure the algae were irradiated for $48 \mathrm{~s}$, we sailed the boat at a speed of $50 \mathrm{~m} / \mathrm{h}$. 
Changes in algal density: Before testing, a large number of algae were seen floating on the water. Through microscopic examination, the major algae species present in the site were Microcystis sp. and Anabaena sp. On the first day, after treating the water with ultrasound for $2 \mathrm{~h}$, the floating algae sank and the density of algae in the water decreased from $(1.10 \pm 0.02)$ $\times 10^{7}$ to $(2.1 \pm 0.1) \times 10^{6}$ cells $/ \mathrm{mL}$. The immediate removal rate obtained reached $80 \%$. After $10 \mathrm{~d}$ of treatment, the algal density in the treatment group was only $(4.40 \pm 0.17) \times 10^{5}$ cells $/ \mathrm{mL}$, whereas in the control group was $(2.01 \pm 0.03) \times$ $10^{7}$ cells $/ \mathrm{mL}$. The algal density of treatment group was only $2.3 \%$ of that of the control group. The changes in the algal density in the water of the test and control groups are shown in Fig. 3a.

Changes in concentration of in vivo Chl-a: Chlorophylla is an important evaluation factor for eutrophication. After 2 $\mathrm{h}$ of the ultrasonic treatment in the first day, the concentration of in vivo Chl-a decreased from $(3.01 \pm 0.03)$ to $(0.41 \pm 0.01)$ $\mathrm{mg} / \mathrm{L}$, which was $13.8 \%$ of the pre-test value. After $10 \mathrm{~d}$ of treatment, the concentration of in vivo Chl-a in the treatment group was only $(0.089 \pm 0.004) \mathrm{mg} / \mathrm{L}$, whereas that in the control group was $(4.3 \pm 0.02) \mathrm{mg} / \mathrm{L}$. The concentration of $i n$ vivo Chl-a in the treatment group was only $2.3 \%$ of that of the control group. The changes in the concentration of in vivo Chl-a in the water of the test and control groups are shown in Fig. 3b. Thus, the frequency and the input power we used were rather low, no negative effect on zooplankton was observed.
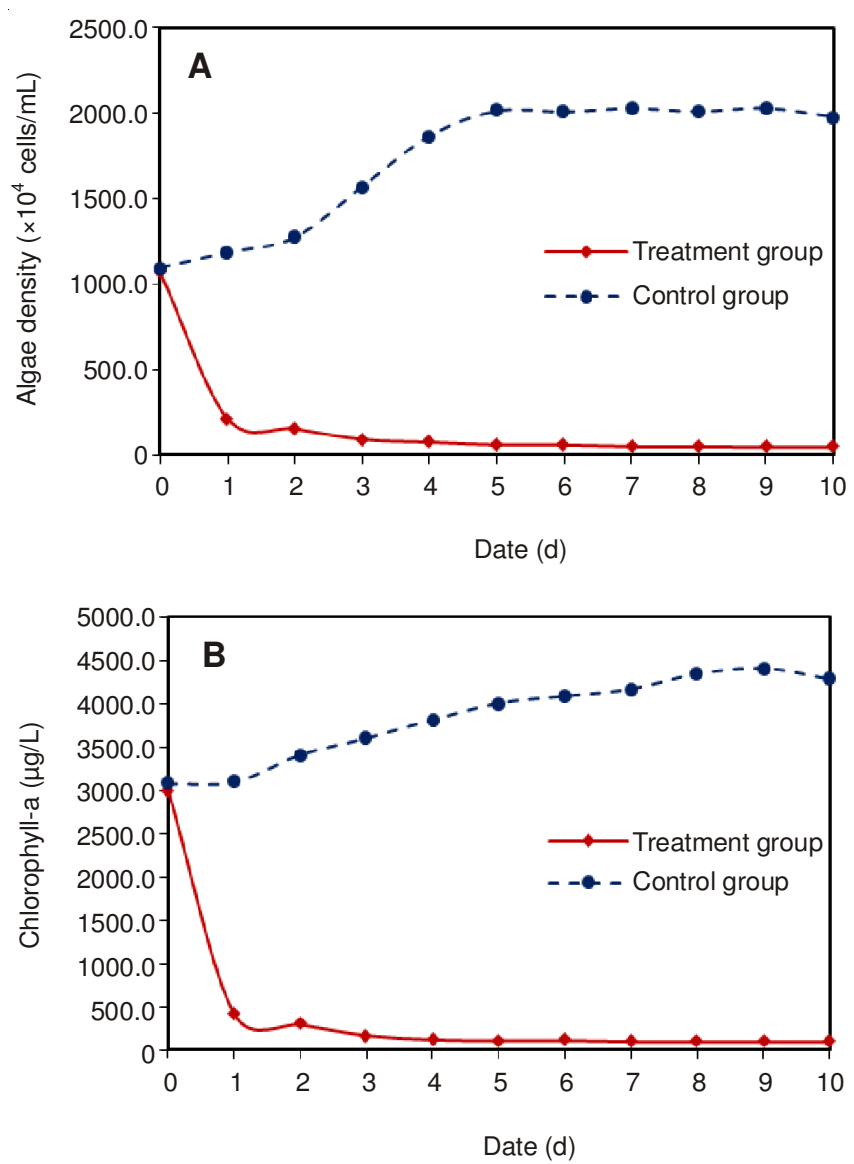

Fig. 4. Changes in quality of control and treated water during the experiment: (a) algae density (b) Chlorophyll-a

\section{Conclusion}

The optimized combination of ultrasound parameters obtained were $45 \mathrm{kHz}$ for ultrasonic frequency, $60 \mathrm{~W}$ for ultrasonic power and $48 \mathrm{~s}$ for ultrasonic irradiation time. The field test confirmed that after the ultrasonic treatment, a large amount of algae in the water sank. After $2 \mathrm{~h}$ of treatment in the first day, algal density decreased from $(1.10 \pm 0.02) \times 10^{7}$ to $(2.1 \pm 0.1) \times 10^{6}$ cells $/ \mathrm{mL}$ and the concentration of in vivo Chl-a decreased to $13.8 \%$ of the initial concentration. All results indicate that ultrasound technology can be applied for the emergency treatment of algal blooms.

\section{ACKNOWLEDGEMENTS}

This work was financially supported by the National Natural Science Foundation of China (51308123), the National Key Science and Technology Special Projects (2009ZX07315002), the Science and Technology Tackle Key Problem in Chongqing (CSTC2010AC7081), Fund of Fuzhou University's Scientific Research Projects (2013-XY-25) and Fund for Fostering Talents of Fuzhou University (XRC-1266).

\section{REFERENCES}

1. V. Ruban, J.F. Lopez-Sanchez, P. Pardo, G. Rauret, H. Muntau and P. Quevauviller, Fresenius J. Anal. Chem., 370, 224 (2001).

2. N. Bury, Comp. Biochem. Physiol. A Mol. Integr. Physiol., 146, S92 (2007).

3. I. Chorus and J. Bartram, Toxic cyanobacteria in water: A guide to their public health consequences, monitoring and management, (Water Health Organization, Geneva, pp. 41-111 (1999).

4. P.C. Turner, A.J. Gammie, K. Hollinrake and G.A. Codd, Br. Med. J., 300, 1440 (1990).

5. A. Rabl, Environ. Health, 5, 1 (2006).

6. L.E. Fleming, C. Rivero, J. Burns, C. Williams, J.A. Bean, K.A. Shea and J. Stinn, Harmful Algae, 1, 157 (2002).

7. M. Yang, J.W. Yu, Z.L. Li, Z.H. Guo, M. Burch and T.F. Lin, Science, 319, 158a (2008).

8. J. Ma and W. Liu, Water Res., 36, 871 (2002)

9. J.J. Chen and H.H. Yeh, Water Res., 39, 4420 (2005).

10. V.K. Thomas, K.A. Kuehn and S.N. Francoeur, J. Freshwat. Ecol., 24, 315 (2009).

11. S. Sato, K. Hirayama and Anon., vol. DIIDW:2003098478 (2003).

12. Y. Tao, X.H. Zhang, D. Au, X.Z. Mao and K. Yuan, Chemosphere, 78, 541 (2010).

13. K. Nakano, T.F. Lee and M. Matsumura, Environ. Sci. Technol., 35, 4941 (2001).

14. C.Y. Ahn, M.H. Park, S.H. Joung, H.S. Kim, K.Y. Jang and H.M. Oh, Environ. Sci. Technol., 37, 3031 (2003).

15. Y. Ding, Y. Pu, L. Yin, X. Qiu, Y. Li and W. Wu, J. Southeast Univ. (Nat. Sci. Ed.), 39, 354 (2009).

16. E.M. Joyce, X. Wu and T.J. Mason, J. Environ. Sci. Health A, 45, 863 (2010).

17. B. Ma, Y. Chen, H. Hao, M. Wu, B. Wang, H. Lv and G. Zhang, Colloids Surf. B, 41, 197 (2005).

18. H.W. Hao, M.S. Wu, W.F. Chen, J.W. Tang and Q.Y. Wu, J. Environ. Sci. Health A, 39, 1435 (2004).

19. J.W. Tang, Q.Y. Wu, H.W. Hao, Y. Chen and M. Wu, Colloids Surf. B, 36, 115 (2004).

20. J. Tang, Q. Wu, H. Hao, Y. Chen and M. Wu, J. Appl. Phycol., 15, 37 (2003).

21. H. Hao, M. Wu, Y. Chen, J. Tang and Q. Wu, Colloids Surf. B, 33, 151 (2004).

22. G. Zhang, P. Zhang, B. Wang and H. Liu, Ultrason. Sonochem., 13, 446 (2006).

23. L. Heng, N. Jun, H. Wen-Jie and L. Guibai, Desalination, 239, 191 (2009).

24. T.J. Lee, K. Nakano and M. Matsumara, Environ. Technol., 22, 383 (2001).

25. G. Zhang, P. Zhang and M. Fan, Ultrason. Sonochem., 16, 334 (2009).

26. D.C. Montgomery, Design and Analysis of Experiments, Wiley \& Sons, New York, edn 6 (2009). 